\title{
The 2011 International Conference on Cohesive Sediment Transport (INTERCOH 2011)
}

\author{
Qing $\mathrm{He}^{1} \cdot$ Johan C. Winterwerp ${ }^{2}$. Andrew James Manning ${ }^{3}$
}

Received: 21 April 2015 / Accepted: 23 April 2015 /Published online: 22 May 2015

(C) Springer-Verlag Berlin Heidelberg 2015

The 11th International Conference of Cohesive Sediment Transport was held in Shanghai, China, during October 1821, 2011. The conference was hosted by the State Key Lab of Estuarine and Coastal Research (SKLEC) at East China Normal University (ECNU). Over 90 researchers worldwide participated in the conference, which included four keynote lectures, and more than 60 oral presentations and 20 posters. All papers appearing in this special issue of Ocean Dynamics are original scientific papers that have been internationally reviewed, focusing on the following:

- Physical processes of fine and mixed sediments: erosion, transport, deposition, flocculation, liquefaction, and consolidation

- Field and laboratory studies of these processes and instrument developments

- Numerical modeling of sediment transport

- Benthic boundary layer processes

- Sediment movements related to wave, turbulence, and rheology

- Morphodynamics of fine and mixed sediments

Responsible Editor: Jörg-Olaf Wolff

Qing He

qinghe@sklec.ecnu.edu.cn

1 State Key Lab of Estuarine and Coastal Research, East China Normal University, 3663 North Zhangshan Road, Shanghai 200062, People's Republic of China

2 Deltares (formerly WL/Delft Hydraulics), PO Box 177, 2600 MH Delft, The Netherlands

3 HR Wallingford, Howbery Park, Wallingford, Oxfordshire OX10 8BA, UK
- Sediment behavior under human interference: dredging, trawling

- Biological and ecological aspects of fine sediment transport processes

This special issue contains 19 papers. The subjects of these papers include two on physical processes, five on field and laboratory studies, six on numerical modeling of fine sediment transport, one on benthic boundary layer processes, one on morphodynamics of fine sediment, two on sediment behavior under human interference, and two on biological aspects of fine sediment transport processes.

An integrated model is necessary for the simulation of the cohesive sediment transport during storm events. Yang et al. (2015) developed an integrated atmosphere-wave-3D hydrodynamic and cohesive sediment transport model. Flocculation and hindered settling for cohesive sediment was included. For the cohesive sediment transport during storm events, the factors of wind, current, and wave all play a dominant role through the wave-induced shear stress which to some degree determined the erosion and deposition fluxes.

Tan et al. (2014) present an experimental study to evaluate, using a laser particle size analyzer under varying flow conditions, the intrinsic particle size distribution (PSD) of two expansive clays, a Ca- and a Na-montmorillonite and the influence of biological, chemical, and hydrodynamic factors on their flocculation and PSD. The significance of understanding the flocculation and PSD of expansive clays is also discussed in terms of sediment transport under different aquatic environments.

What is the influence of downstream morphology behind dams in the Yangtze River? In order to evaluate the change in grain size on the tidal flats of the Yangtze Estuary, a highly schematized tidal flat model is setup and broadly reveals that observed deposition rates are large because of the high 
sediment concentration, the abundance of silt and seasonal waves and offshore tidal asymmetry. van Maren et al. (2013) point out that the deposition rate will be marginally influenced by reductions in clay or fine silt but strongly impacted by reductions in median to coarse silt.

Van Prooijen and Wang (2013) propose a new way of schematizing a complex tidal basin into a $1 \mathrm{D}$ basin. A new formulation for erosion of fines from a sandy bed is proposed in the transport equation for fine sediment. The model gives direct insights in the variation of bed shear stresses, suspended sediment concentrations, and mud fractions in the bed.

Chen et al. (2013) measure the micro-morphology and surface charge distribution of quartz sand using the electrical force microscope. A statistical relationship between micro-morphology and surface charge distribution is obtained. A fitting equation between surface charge and non-spherical curvature is also obtained.

Vested et al. (2013) develop a method to simulate longterm morphodynamics of estuaries dominated by fine sediments, which are subject to both tidal flow and freshwater discharge and wave conditions. The models and scaling factors are applied to predict the morphological development over a time scale of up to 10 years.

Verhagen et al. (2013) examine the feedback processes that occur when particulate density currents move over a soft mud substrate. Five different interaction types are described, and dimensional and non-dimensional phase diagrams for flowbed interaction are presented.

Jiang et al. (2013) explain the changes in net sediment transport in terms of physical mechanisms in the North Passage of the Yangtze Estuary. The SSC revealed that the estuaries turbidity maximum was intensified due to the deep water project, especially in the wet season, and an upstream shift and extension of the ETM zone occurred.

Vanlede and Dujardin (2014) apply geometric analysis method to study the exchange flow and sediment between a harbor and the surrounding water. The method can provide some insight into the complex relationship between hydrodynamics and sediment concentration that determines harbor siltation.

Hejazi et al. (2013) developed a numerical model to simulate wave-mud interaction. Application of the new model in a combined system of viscous fluid mud shows good agreement in determining damping and water-mud interface elevation for various wave heights and frequencies compared to experimental data.

Lee et al. (2014) study multimodal particle size distribution of fine-grained cohesive sediment. Four modal peaks, consisting of four-level ordered structures of primary particles, flocculi, microflocs, and macroflocs, were identified and found to alternately rise and sink in a flow-varying tidal cycle due to shear-dependent flocculation.

$\mathrm{Li}$ et al. (2013) use field work data to discuss the sediment transport process and formation mechanism of the mud depocenter off the Zhejiang- Fujian coast in the inner shelf of the
East China Sea. The results suggest that winter is the key season for sediment transport and deposition. The turbid layer is the primary channel of sediment transport.

Liu et al. (2013) investigate the consolidation processes acting on an intertidal mudflat in the Yellow River delta. Results show that sediment discharge from the Yellow River experienced a high rate of consolidation after initial deposition.

de Lucas Pardo et al. (2013) study the water-bed exchange processes of a lake's muddy bed. The objective of the study is to determine the influence of the development of the thin oxic layer on the water-bed exchange processes, as well as to establish the role of bioturbation on those processes.

Soltanpour et al. (2015) test the effect of a thin fluid layer on near shore by numerical model and wave basin experiments. The results can be utilized for better understanding of the complex wave transformation phenomena under real field conditions.

Niu and Yu (2014) develop a numerical model for wave propagation over a multilayered muddy seabed. It is found that the underlying mud layer plays a very important role in the wave-mud interaction and greatly affects the wave decay rate.

te Slaa et al. (2013) analyze the settling and consolidation behavior of silt-rich sediment under laboratory conditions in specially designed settling columns. The settling behavior of silt-rich sediment is found to be in analogy with granular material at concentration below $150 \mathrm{~g} / \mathrm{l}$. Above 150-200 g/l, the material settles in a hindered settling regime where segregation is limited or even prevented.

Nakagawa et al. (2012) describe the persistent existence of fluid mud in Tokyo Bay, with thickness of a few decimeters. This fluid mud may be the result of abundant organic material, formed under eutrophic conditions in the bay. A diffusion model was setup and calibrated for estimating the vertical distribution of suspended sediment in the fluid mud layer and vertical flux of that sediment near the bed.

Zhang et al. (2013) model the development of floc characteristics at early stage and steady-state of flocculation. Model results show that the normalized floc size distribution is timeindependent during early stage of flocculation, and at steadystate, shear rate has no effect on the shape of the normalized floc size distribution.

We would like to thank the State Key Lab of Estuarine and Coastal Research (SKLEC), National Science Foundation of China (NSFC) and the Science and Technology Commission of Shanghai Municipality (STCSM) for their financial support. Furthermore, we gratefully acknowledge the animated and skillful help of the group of voluntary staffs and students of SKLEC. We also thank the Chief Editor Prof. Jörg-Olaf Wolff of Ocean Dynamics for his great help and encouragement throughout the preparation of this special issue. Last but not least, we thank all INTERCOH steering committee members and all the reviewers for their dedication to scientific rigors that makes this special issue so valuable to the scientific community. 


\section{References}

Chen M-H, Fang H-W, Huang L (2013) Surface charge distribution and its impact on interactions between sediment particles. Ocean Dyn 63:1113-1121. doi:10.1007/s10236-013-0641-1

de Lucas Pardo MA, Bakker M, van Kessel T, Cozzoli F, Winterwerp JC (2013) Erodibility of soft freshwater sediments in Markermeer: the role of bioturbation by meiobenthic fauna. Ocean Dyn 63:11371150. doi:10.1007/s10236-013-0650-0

Hejazi K, Soltanpour M, Sami S (2013) Numerical modeling of wavemud interaction using projection method. Ocean Dyn 63:10931111. doi:10.1007/s10236-013-0637-x

Jiang C, de Swart HE, Li J, Liu G (2013) Mechanisms of along-channel sediment transport in the North Passage of the Yangtze Estuary and their response to large-scale interventions. Ocean Dyn 63:283-305. doi:10.1007/s10236-013-0594-4

Lee BJ, Toorman E, Fettweis M (2014) Multimodal particle size distributions of fine-grained sediments: mathematical modeling and field investigation. Ocean Dyn 64:429-441. doi:10.1007/s10236-0140692-y

Li Y, Qiao L, Wang A, Zhang Y, Fang J, Chen J (2013) Seasonal variation of water column structure and sediment transport in a mud depocenter off the Zhejiang-Fujian Coast in China. Ocean Dyn 63:679690. doi:10.1007/s10236-013-0620-6

Liu X, Jia Y, Zheng J, Yang X, Shan H (2013) Consolidation of sediments discharged from the Yellow River: implications for sediment erodibility. Ocean Dyn 63:371-384. doi:10.1007/s10236-013-0599-z

Nakagawa Y, Nadaoka K, Yagi H, Ariji R, Yoneyama H, Shirai K (2012) Field measurement and modeling of near-bed sediment transport processes with fluid mud layer in Tokyo Bay. Ocean Dyn 62: 1535-1544. doi:10.1007/s10236-012-0570-4

Niu X, Yu X (2014) Numerical study on wave propagation over a fluidmud layer with different bottom conditions. Ocean Dyn 64:293300. doi:10.1007/s10236-013-0686-1
Soltanpour M, Haghshenas SA, Shibayama T (2015) A two-dimensional experimental-numerical approach to investigate wave transformation over muddy beds. Ocean Dyn 65:295-310. doi:10.1007/ s10236-014-0797-3

Tan X, Hu L, Reed AH, Furukawa Y, Zhang G (2014) Flocculation and particle size analysis of expansive clay sediments affected by biological, chemical, and hydrodynamic factors. Ocean Dyn 64:143157. doi:10.1007/s10236-013-0664-7

te Slaa S, He Q, van Maren DS, Winterwerp JC (2013) Sedimentation processes in silt-rich sediment systems. Ocean Dyn 63:399-421. doi:10.1007/s10236-013-0600-x

van Maren DS, Yang S-L, He Q (2013) The impact of silt trapping in large reservoirs on downstream morphology: the Yangtze River. Ocean Dyn 63:691-707. doi:10.1007/s10236-013-0622-4

van Prooijen BC, Wang ZB (2013) A 1D model for tides waves and fine sediment in short tidal basins - application to the Wadden Sea. Ocean Dyn 63:1233-1248. doi:10.1007/s10236-013-0648-7

Vanlede J, Dujardin A (2014) A geometric method to study water and sediment exchange in tidal harbors. Ocean Dyn 64:1631-1641. doi: 10.1007/s10236-014-0767-9

Verhagen ITE, Baas JH, Silva Jacinto R, McCaffrey WD, Davies AG (2013) A first classification scheme of flow-bed interaction for clay-laden density currents and soft substrates. Ocean Dyn 63: 385-397. doi:10.1007/s10236-013-0602-8

Vested HJ, Tessier C, Christensen BB, Goubert E (2013) Numerical modelling of morphodynamics-Vilaine Estuary. Ocean Dyn 63: 423-446. doi:10.1007/s10236-013-0603-7

Yang X, Zhang Q, Zhang J, Tan F, Wu Y, Zhang N, Yang H, Pang Q (2015) An integrated model for three-dimensional cohesive sediment transport in storm event and its application on Lianyungang Harbor, China. Ocean Dyn 65:395-417. doi:10.1007/s10236-0140806-6

Zhang J-F, Zhang Q-H, Maa JPY, Qiao G-Q (2013) Lattice Boltzmann simulation of turbulence-induced flocculation of cohesive sediment. Ocean Dyn 63:1123-1135. doi:10.1007/s10236-013-0646-9 